\title{
DIELECTRIC SPECTROSCOPIC EVALUATION IN THE EXTREMELY LOW FREQUENCY RANGE OF AN ASPERGILLUS NIGER CULTURE
}

\author{
MÓNIKA LINGVAYa,b, ALINA-RUXANA CARAMITUc, \\ ADRIANA-MARIANA BORȘ ${ }^{\mathbf{d}^{*}}$, IOSIF LINGVAYc
}

\begin{abstract}
By using the dielectric spectroscopy technique in the extremely low frequency $(1-200 \mathrm{~Hz})$ range, dielectric loss tg $\delta$ was determined on both Aspergillus niger cultures in different growth stages and autoclaved biomass compared to the Czapex-Dox culture medium with sterile sucrose.

Experimental results have shown that living and sterile matter samples have different dielectric characteristics. In sterile probes, the evolutionary functions of $\operatorname{tg} \delta$ depending on frequency are continuous, specific to $\alpha-$ relaxation governed by DC electrical conductivity. In living matter samples, the function of dielectric losses $t g \delta$, depending on frequency, show several discontinuities that indicate the existence of some processes in which, at those frequencies, the number of charge carriers from investigated living matter is changing. It has also been found that the package of active processes differs depending on the growth stage of Aspergillus niger.
\end{abstract}

Keywords: ELF electromagnetic fields, dielectric loss, relaxation dynamics, $\alpha$-relaxation, fungi

a Babeş-Bolyai University, Faculty of Chemistry and Chemical Engineering, 11 Arany János str., RO-400028, Cluj-Napoca, Romania

${ }^{b}$ Present affiliation: University of Szeged, Faculty of Science and Informatics, Doctoral School of Physics, 9 Dóm tér, H-6720, Szeged, Hungary

${ }^{c}$ National Institute for Research and Development in Electrical Engineering INCDIE ICPE-CA, 313 Splaiul Unirii, RO-030138, Bucharest, Romania

d ICPE SA, 313 Splaiul Unirii, RO-030138, Bucharest, Romania

*Corresponding author: adrianambors@gmail.com 


\section{INTRODUCTION}

In the perspective of sustainable development, ensuring healthy working and living conditions is a priority issue [1]. At present day, an essential condition for the quality of human life is to provide the necessary electricity.

The production, transmission / distribution and use of electricity involves generation of electromagnetic fields (EMF) which, by AC (alternating current) polarization, on the one hand, influence the mechanism and kinetics of the natural bioelectrochemical processes [2] specific to the living matter and, on the other hand, accelerate corrosion and / or material degradation processes (both oxide [3] and polymeric [4]) from the buildup media [5-8].

Research studies have shown that, depending on their intensity and frequency, EMF can modify certain biochemical processes and thus have an influence on the behavior of living matter [9-19] exposed to EMF of anthropogenic origin. Findings have shown that the EMF influences on the living matter are largely influenced by the experimental conditions, namely the frequency and intensity of the applied EMF, the dielectric characteristics of the sample materials, the geometry of the experimental cells / bioreactors [20], etc. EMF of anthropogenic origin can influence the organisms, both in a positive (growth stimulation [15, 21, 22]) and negative way (inhibition of growth $[21,23])$. Growth stimulating of microorganisms (bacteria, microalgae, fungi etc.) and plants in EMF can be a way of streamlining various biotechnological processes such as biofuel production from algae, biodegradation of waste, water purification [21, 22] —including those containing xenobiotic substances-, etc. On the other hand, one can notice that excessive increase of the applied electric field leads to membrane permeabilization and subsequent leakage of intracellular compounds [15, 24].

The effects of exposure to EMF on living matter are differentiated according to the frequency of the perturbative field. Thus, several studies have emphasized that $50 \mathrm{~Hz}$ EMF diminishes melatonin production, thus causing disturbances of circadian rhythm with consequences on the immune system and increasing the incidence of different cancers [25-27]. Furthermore, researchers have also highlighted their influences on human leukemia cell line HL-60 [28] and on the intramicrovascular leukocyte behavior in mice [29]. Further various effects of exposure to $50 \mathrm{~Hz}$ EMF on human cells have been reported in [30-35]. In [36, 37], various biological effects of high- and very high frequency EMF have been presented. Associations between EMF and immune and oxidative response have been found in people professionally exposed to EMF in the 140-160 MHz band [38]. Various biological effects, namely modifications in enzymatic activity [39], cellular proliferation of nucleated erythropoietic cells [40-42], oxidative stress [43, 44], etc., have been reported for EMF exposures in the radio frequency band. Also, a lot of studies have shown the harmful effects of mobile telephony on the human brain [45-48]. 
Relaxation dynamics of protein solutions involves changes of the dielectric permittivity and conductivity of the living matter. Studies on the dielectric characteristics of protein solutions have been reported since 1938 [49]. The dielectric spectroscopy method allows analysis of the dielectric characteristics' evolution of the materials, as a function of the frequency of the applied electric signal [50]. Thus, many authors have applied this technique for studying the dielectric relaxation in biological systems or protein solutions $[11,51-56]$. From these studies, can be concluded that the relaxation phenomena are differentiated according to the frequency band, respectively in the $1-1000 \mathrm{MHz}$ band dominating is the $\beta$-relaxation (relaxation of the proteins in aqueous environment), in $0.1-10 \mathrm{GHz}$ band the $\delta$-dispersion (relaxation of the protein-bound water molecules), and over $10 \mathrm{GHz}$ the $\mathrm{y}$-dispersion (rotational diffusion of water dipoles).

Mass and electrical charge transport have fundamental significance for the function and activity of biological systems. Cellular electrical polar structures with energy supply (such as microtubules) can become excited and generate an endogenous electric field. Endogenous electric field can have dominant effect on directed transport of molecules and electrons such that the probability to reach the target is enhanced in comparison with random thermal motion [57]. It is noted that by overlapping an external EMF on the endogenous electric field of biological systems, the field resulting from the vectorial composition of these can influence (favourably or unfavourably) the cellular transport processes of molecules and electrons and, implicitly, the behaviour of the organism. In this context, the effect of a transmembrane $\mathrm{AC}$ field in the $1 \mathrm{~Hz}-10 \mathrm{kHz}$ range on the biochemical activity of a native yeast vacuolar proton-ATPase (V-ATPase) had been reported recently [58], where the externally applied field generally inhibited the enzyme's rotational activity, except for a region peaking around $86 \mathrm{~Hz}$, at which frequency, the field was able to synchronize the steps of ion-pumping in individual enzymes via a hold-and-release mechanism. It has been experimentally found that the $50 \mathrm{~Hz}$ electric field stimulates the growth and reproduction (production of spores) of Aspergillus niger [15].

Thus, the aim of present study is to probe a biomass of Aspergillus niger filamentous fungi in different stages of growth on sucrose medium by dielectric spectroscopy technique.

\section{Results and Discussion}

Dielectric losses $\operatorname{tg} \delta$ in the $1-200 \mathrm{~Hz}$ range have been determined applying the method of dielectric spectroscopy. 
The $\varepsilon$ dielectric permittivity of the materials is a frequency-dependent complex parameter and is given by the relation (1):

$$
\varepsilon(\omega)=\varepsilon^{\prime}+j \varepsilon^{\prime \prime}
$$

where $j$ represents the imaginary unit $(\sqrt{-1})$, and the value of the imaginary component $\varepsilon^{\prime \prime}$, is determined by the electrical conductivity of the material, given by the number and the charge carriers mobility (at given temperature). The dielectric loss $\operatorname{tg} \delta$ is the ratio between the imaginary $\varepsilon^{\prime \prime}$ and the real $\varepsilon^{\prime}$ component of the dielectric permittivity of the materials and is directly proportional with the electrical conductivity of the material, respectively (2):

$$
\operatorname{tg} \delta=\frac{\varepsilon^{\prime \prime}}{\varepsilon^{\prime}}
$$

Experimental determinations were performed on samples of sterile Czapex-Dox culture medium with sucrose (reference), from an Aspergillus niger culture after 36 hours and 84 hours of incubation, as well as from the sterilized resulting biomass.

The comparative determination's results are presented in Figure 1.

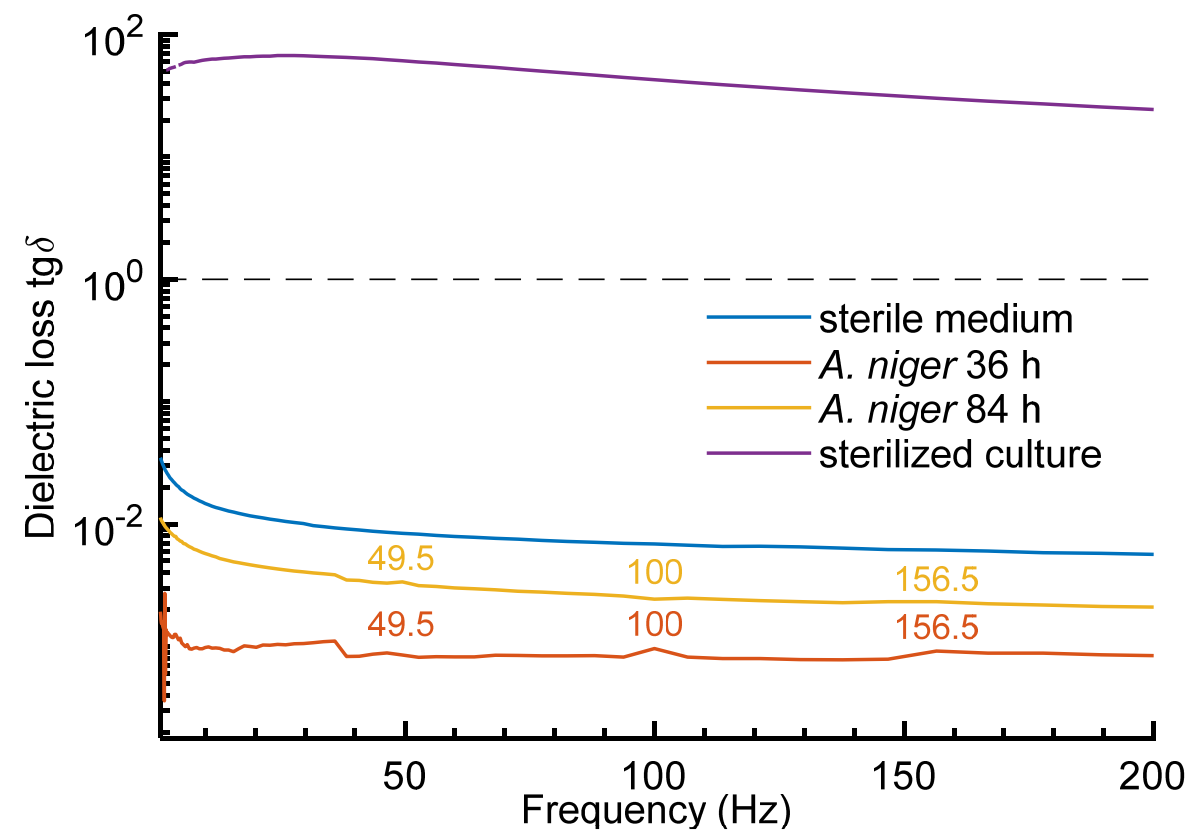

Figure 1. Dielectric losses of investigated samples 
From the analyses of Figure 1 one can notice that the dielectric losses $\operatorname{tg} \delta$, both in the reference sample (blue curve) and in the incubated and sterilized sample (Aspergillus niger biomass in culture medium sterilizedviolet curve) show a continuous evolution in function of frequency. Values smaller with about three order of magnitude obtained on the initial (reference) culture medium compared to those obtained on autoclaved biomass indicate that the number of charge carriers in the sample (and, implicitly, electrical conductivity) increases during the incubation (growth of Aspergillus niger). The number of charge carriers in the reference sample being given by the mineral salt content of the culture medium, this behaviour indicates that during the growth of Aspergillus niger, following the metabolism of sucrose, new electroconductive species were formed-such as proteins, which have a net-negative charge at neutral $\mathrm{pH}$ of cells, as well as the protons and anions of citric and oxalic acids formed by the metabolism of sucrose [14, 59].

By the comparative analysis of the dielectric behaviour of sterile samples (reference sample and autoclaved biomass) with those containing living matter (samples taken after $36 \mathrm{~h}$-red curve-and $84 \mathrm{~h}$ of incubationyellow curve), can be noticed that in the first 36 hours of growth $\operatorname{tg} \delta$ decreases about tenfold relative to the reference sample, the decrease being less pronounced at 84 hours of incubation (about threefold). This behaviour can be explained by the fact that developing cells draw the necessary mineral ions from the culture medium to the cytoplasm across the plasma membrane-to maintain a relatively constant specific ionic composition of the cytosol-, reducing in this way the number of free charge carriers from the surrounding fluid and implicitly the electrical conductivity of the sample. The threefold increase of $\operatorname{tg} \delta$ of the $84 \mathrm{~h}$-sample compared to the $36 \mathrm{~h}$-one is explained by the higher amount of charge carriers / metabolites formed during the growth of biomass and eliminated in the extracellular space. Under these conditions, the spectacular increase of $\operatorname{tg} \delta$ following autoclaving (when disruption of bonds within cell walls and protein denaturation occurs) can be explained by "emptying" the intracellular space composition, together with dissociated inorganic salts and organic charged metabolites, into the extracellular space. The electrical conductivity of the sample is given by the total content of mineral salts and metabolic products originated from the cytoplasmic space.

Figure 1 shows a net-different dielectric behaviour of sterile samples (autoclaved medium and culture) from the living samples ( $36 \mathrm{~h}$ and $84 \mathrm{~h}$ of incubation). Unlike sterile samples, where $\operatorname{tg} \delta$ evolution functions are continuous and specific to $\alpha$-relaxation governed by DC electrical conductivity [50] in living matter samples these functions show discontinuities at certain frequencies (noticeable in Figure 1 and 2). These discontinuities indicate the presence of dynamic processes that are influenced at the respective frequencies by the electric field action generated by the measuring signal, so that the number of 
charge carriers in the investigated matter changes. This kind of behaviour could be attributed to different transmembrane ion-transporting proteinse.g. V-ATPase proton pumps, whose rotational rate can be determined by synchronizing the ion-pumping steps of individual enzymes with a transmembrane AC field [58]. Figure 2 shows the evolution of $\operatorname{tg} \delta$ as function of frequency in the $1-60 \mathrm{~Hz}$ range (extension from Figure 1).

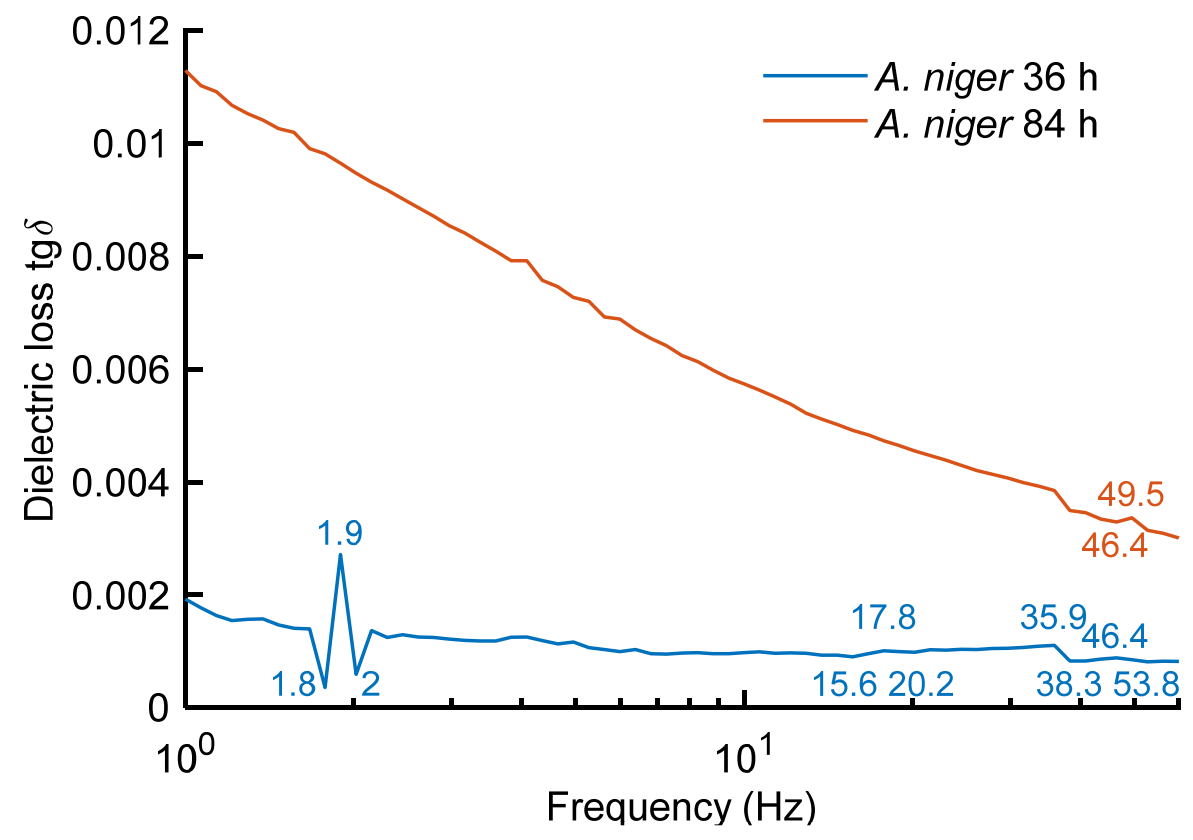

Figure 2. Dielectric losses of investigated samples with living matter

Analysing Figure 2 one can notice that in case of the $36 \mathrm{~h}$-sample, beside the discontinuities from $\sim 38.3, \sim 49.5,100$, and $156.5 \mathrm{~Hz}$ (with higher amplitude), those from 1.9 and $17.8 \mathrm{~Hz}$ can be also identified. This finding suggests that the package of proteins and enzymes operating at the early growth phase (formation of hyphae) and the phase of maturation growing stages of Aspergillus niger differ from each other at some extent, or several processes have different intensity at different times.

Under these conditions, it is very likely that by applying an external AC electric field it is possible to selectively control (stimulate/inhibit) the activity of proteins (especially ionic pumps) and implicitly the biochemical processes controlled by these. This aspect can explain both the stimulation of Aspergillus niger growth in the $50 \mathrm{~Hz}$ electric field [15], and the extremely low EMF effects reported [25-29]. 


\section{CONCLUSIONS}

By dielectric spectroscopy measurements in the $1-200 \mathrm{~Hz}$ range, the dielectric loss $\operatorname{tg} \delta$ was determined on both Aspergillus niger cultures in different growth stages and autoclaved biomass culture, compared to sterile medium (reference).

The experimental results have shown that samples with Aspergillus niger cultures had a different dielectric behaviour than sterile samples (culture medium and autoclaved biomass): for latter ones the evolution functions of $\operatorname{tg} \delta$ are continuous, unlike samples of living matter, for which these functions have several discontinuities.

It has also been found that the processes performed in the first growing stage of the Aspergillus niger culture are different from those in the more advanced development stage (maturation).

These results suggest that an $\mathrm{AC}$ field with given frequency is able to selectively control the activity of several enzymes and other ion-transporting assemblies, which opens up the possibility of biotechnological exploitation.

\section{EXPERIMENTAL SECTION}

Sterile Czapex-Dox growth medium was prepared by autoclavation of $1000 \mathrm{~mL}$ aqueous solution in which $30 \mathrm{~g}$ sucrose, $2 \mathrm{~g} \mathrm{NaNO}_{3}, 0.7 \mathrm{~g} \mathrm{KH}_{2} \mathrm{PO}_{4}$, $0.3 \mathrm{~g} \mathrm{~K}_{2} \mathrm{HPO}_{4}, 0.5 \mathrm{~g} \mathrm{KCl}, 0.5 \mathrm{~g} \mathrm{MgSO}_{4} \times 7 \mathrm{H}_{2} \mathrm{O}, 0.01 \mathrm{~g} \mathrm{FeSO}_{4}$, and $30 \mathrm{~g}$ of Agar (for gelification) was dissolved. All reagents were of analytical grade and were purchased from Merck.

As inoculum, a suspension in basic mineral solution (about $10^{6}$ spores $/ \mathrm{mL}$ ) of Aspergillus niger spores was used. Inoculated cultures were incubated in the dark for $84 \mathrm{~h}$ at $30 \pm 2{ }^{\circ} \mathrm{C}$, relative humidity $90 \pm 5 \%$.

Sterilization of the biomass grown on the culture medium was done by autoclavation for $30 \mathrm{~min}$ at $105 \pm 3^{\circ} \mathrm{C}$.

Growth medium samples were taken before inoculation (reference), after $36 \mathrm{~h}$ and $84 \mathrm{~h}$ of incubation, and after sterilization of the biomass, respectively.

Dielectric spectroscopic measurements in the $1-200 \mathrm{~Hz}$ range were carried out using a 1296A Dielectric Interface System (Solartron Analytical / AMETEK Scientific Instruments, USA). Collected spectral data were analysed using the Spectr-O-Matic MATLAB® toolbox. 
MÓNIKA LINGVAYA, ALINA-RUXANA CARAMITUB, ADRIANA-MARIANA BORȘC, IOSIF LINGVAY

\section{ACKNOWLEDGMENTS}

The work was performed under contracts PN II no.100/2014 and 30PFE/2018 between National R\&D Institute for Electrical Engineering ICPE-CA and Romanian Ministry of Research and Innovation (MCl).

\section{REFERENCES}

1. E.A. Stere, I. Popa; Electrotehnica, Electronica, Automatica (EEA), 2018, 66 (3), $125-136$

2. I. Lingvay, C. Lingvay, A. Voina; Rev. Roum. Sci. Tech. El., 2008, 53 (2bis), 8594

3. C. Lingvay, A. Cojocaru, T. Vişan, I. Lingvay; U.P.B. Sci. Bull. Series B, 2011, 73 (4), 143-152

4. A. Caramitu, N. Butoi, T. Rus, A.M. Luchian, S. Mitrea; Mat. Plast., 2017, 54 (2), 331-337

5. I. Szatmari, M. Lingvay, L. Tudosie, A. Cojocaru, I. Lingvay; Rev. Chim. (Bucharest), 2015, 66 (3), 304-311

6. I. Lingvay, M. Gabor, C. Lingvay, Rev. Chim. (Bucharest), 2006, 57 (2), 180-183

7. I. Lingvay, C. Lingvay, C. Homan, O. Ciogescu; Rev. Chim. (Bucharest), 2006, 57 (12), 1279-1282

8. I. Lingvay, A.M. Bors, D. Lingvay, L. Radermacher, V. Neagu; Rev. Chim. (Bucharest), 2018, 69 (12), 3593-3599

9. B. Yokus, M.Z. Akdag, S. Dasdag, D.U. Cakir, M. Kizil; Int. J. Radiat. Biol., 2008 , 84 (10), 789-795

10. D. Sandu, I. Lingvay, S. Lányi, D.D. Micu, C.L. Popescu, J. Brem, L.C. Bencze, C. Paizs; Stud. Univ. Babes-Bolyai, Chem., 2009, 54 (4), 195-201

11. C. Stancu, M. Lingvay, I. Szatmári, I. Lingvay; The 8th Int. Symp. on ATEE, Bucharest, Romania, May 23-25, 2013, 1-4

12. A.H. Hashish, M.A. El-Missiry, H.I. Abdelkader, R.H. Abou-Saleh; Ecotoxicol. Environ. Saf., 2008, 71, 895-902

13. A. Amarolia, M.G. Chessaa, G. Bavestrello, B. Bianco; Eur. J. Protistol., 2013, 49, 400-405

14. M. Gao, J. Zhang, H. Feng; Bioelectromagnetics, 2011, 32, 73-78

15. E. Radu, D. Lipcinski, N. Tănase, I. Lingvay; Electrotehnica, Electronica, Automatica (EEA), 2015, 63 (3), 68-74

16. D.I. de Pomerai, B. Smith, A. Dawe, K. North, T. Smith, D.B. Archer, I.R. Duce, D. Jones, P. Candido; IEEE Trans. Microw. Theory, 2000, 48, 2076-2081

17. Y.J. Huang, J. Samorajski, R. Kreimer, P.C. Searson; PLoS One, 2013, 8 (3), e59447. DOI: 10.1371/journal.pone.0059447

18. S. Kwee, P. Raskmark, S. Velizarov; Electro- Magnetobiol., 2001, 20, 141-152

19. T. Shigemitsu, K. Yamazaki, S. Nakasono, M. Kakikawa; IEEJ Trans. Electr. Electron. Eng., 2007, 2 (4), 405-412 
DIELECTRIC SPECTROSCOPIC EVALUATION IN THE EXTREMELY LOW FREQUENCY RANGE OF AN ASPERGILLUS NIGER CULTURE

20. M. Lingvay, L. Czumbil; Electrotehnica, Electronica, Automatica (EEA), 2014, 62 (3), 84-89

21. R.W. Hunt, A. Zavalin, A. Bhatnagar, S. Chinnasamy, K.C. Das; Int. J. Mol. Sci., 2009, 10, 4515-4558

22. J. Filipič, B. Kraigher, B. Tepuš, V. Kokol, I. Mandic-Mulec; Bioresour Technol. 2012, 120, 225-232

23. M. Racuciu, C. Iftode, S. Miclaus; Rom. J. Phys., 2015, 60 (3-4), 603-612

24. K. Aronsson, U. Rfnner, E. Borch, Int. J. Food Microbiol., 2005, 99, 19-32

25. O. Hiwaki; Engineering in Medicine and Biology Society, Proceedings of the 20th Annual International Conference of the IEEE, 1998.

DOI: 10.1109/IEMBS.1998.746203

26. Y. Touitou, B. Selmaoui; Dialogues Clin Neurosci. 2012, 14 (4), 381-399

27. B. Lewczuk, G. Redlarski, A. Żak, N. Ziółkowska, B. Przybylska-Gornowicz, M. Krawczuk; BioMed Res. Int., 2014, ID 169459

28. D. Sztafrowski, Z. Wroblewski, M. Lukaszewicz, A. Sikorski, M. Majkowski; 10th EEEIC, 2011. DOI: 10.1109/EEEIC.2011.5874726

29. A. Ushiyama, Y. Suzuki, H. Masuda, S. Hirota, M. Taki, C. Ohkubo; Proceedings of Radio Science Conference, 2004

DOI: 10.1109/APRASC.2004.1422506

30. A.C. Mannerling, M. Simkó, K.H. Mild, M.O. Mattsson; Radiat. Environ. Biophys., 2010, 49, 731-741

31. M.O. Mattsson, M. Simko; Toxicology, 2012, 301, 1-12

32. M. Lupke, J. Rollwitz, M. Simkó; Free Radic. Res., 2004, 38, 985-993

33. M. Lupke, J. Frahm, M. Lantow, C. Maercker, D. Remondini, F. Bersani, M. Simkó; Biochim. Biophys. Acta, 2006, 1763, 402-412

34. M.O. Mattsson, M. Simko; Front. Public Health, 2014, 2, 132.

DOI: 10.3389/fpubh.2014.00132

35. M. Simkó, M.O. Mattsson; J. Cell. Biochem., 2004, 93 (1), 83-92

36. D. Popescu, R. Anton; Arch. Biol. Sci., 2015, 67, 895-897

37. E.S. Bechir, F. Bechir, B. Vladila; Rev. Chim (Bucharest), 2018, 69 (12), 37053709

38. D. Dabala, D. Surcel, C. Szanto, S. Miclăus, M. Botoc, S. Toader, O. Rotaru; Rev. Roum. Sci. Tech. El., 2008, 53 (2bis), 21-30

39. R. Paulraj, J. Behari; Electro- Magnetobiol., 2002, 21, 221-231

40. S. Velizarov, P. Raskmark, S. Kwee; Bioelectrochem. Bioenerg., 1999, 48, 177180

41. I. Trosic, I. Busljeta, V. Kasuba, R. Rozgaj; Mutat. Res., 2002, 521, 73-79

42. I. Busljeta, I. Trosic, S. Milkovic-Kraus; Int. J. Hyg. Environ. Health, 2004, 207, 549-554

43. M. Zmyslony, P. Politanski, E. Rajkowska, W. Szymczak, J. Jajte; Bioelectromagnetics, 2004, 25, 324-328

44. I. Meral, H. Mert, N. Mert, Y. Deger, I. Yoruk, A. Yetkin, S. Keskin; Brain Res., 2007, 1169, 120-124

45. N.D. Volkow, D. Tomasi, G.J. Wang, P. Vaska, J.S. Fowler, F. Telang, D. Alexoff, J. Logan, C. Wong; JAMA, 2011, 305 (8), 808-813.

DOI: 10.1001/jama.2011.186 
46. R.B. Dubey, M. Hanmandlu, S.K. Gupta; J Comput Assist Tomogr, 2010, 34 (6), 799-807

47. N.D. Volkow, D. Tomasi, G.J. Wang, J.S. Fowler, F. Telang, R. Wang, D. Alexoff, J. Logan, C. Wong, K. Pradhan, E.C. Caparelli, Y. Ma, M. Jayne; Neuroimage., 2010, 51 (2), 623-628

48. M. Barteri, A. Pala, S. Rotella; Biophys. Chem., 2004, 113, 245-253

49. J.L. Oncley; J. Am. Chem. Soc.,1938, 60, 1115-1123

50. Valerică Raicu, Yuri Feldman; Dielectric Relaxation in Biological Systems Physical Principles, Methods, and Applications, OXFORD University Press, New York, 2015, Chapter 2.

51. I. Wolf, R. Gulich, P. Lunkenheimer, A. Loidl; Biochim. Biophys. Acta, Proteins Proteomics, 2012,1824 (5), 723-730

52. K. Asami; Bioelectrochemistry, 2013, 92, 14-21

53. J.L. Sebastian Franco, A. Sanchis Otero, J. R. Madronero, S. M. San Martin; Prog. Electromagn. Res., 2013, 134, 211-222

54. M. Lingvay, C. Stancu, I. Szatmári, I. Lingvay; Electrotehnica, Electronica, Automatica (EEA), 2013, 61 (1), 43-47

55. M. Stoneman, A. Chaturvedi, D. Jansma, M. Kosempa, C. Zeng, V. Raicu; Bioelectrochemistry; 2007, 70 (2), 542-550

56. I. Rodríguez-Arteche, S. Cerveny, Á. Alegría, J. Colmenero; Phys. Chem. Chem. Phys., 2012, 14 (32), 11352-11362

57. J. Pokorný, J. Hašek, F. Jelínek; J. Biol. Phys., 2005, 31 (3-4), 501-514

58. C.M. Ferencz, P. Petrovszki, A. Dér, K. Sebők-Nagy, Z. Kóta, T. Páli, Sci. Rep., 2017, 7, 45309. DOI: 10.1038/srep45309

59. Y.L. Ramachandra, G. Narayanamurthy, S. Jois; Adv. Biol. Res., 2013, 7, 234240 